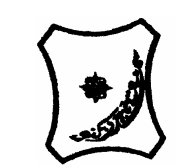

Bayero Journal of Pure and Applied Sciences, 2(2); 197 - 202

Received: October, 2009

Accepted: November, 2009

\title{
FABRICATION AND STUDY OF THE ELECTRICAL PROPERTIES OF PbO/Fe BASED COMPOSITE RESISTORS
}

\author{
A. O. Musa ${ }^{1}$ and Mohammad, L. Madugu ${ }^{2}$ \\ ${ }^{1}$ Department of Physics, Bayero University, Kano. \\ ${ }^{2}$ Department of Physics, Gombe State University, Gombe. \\ *Correspondence Author
}

\begin{abstract}
Lead Oxide and Iron based composite resistors of constant diameter $(0.6 \mathrm{~cm})$ and varying lengths ranging from 0.37 to $1.17 \mathrm{~cm}$ were fabricated. The resistors were fabricated by the use of a moulder with the application of an average pressure of $1.5 \times 10^{6} \mathrm{Nm}^{-2}$. The research is aimed at fabrication and study of the electrical properties of cermets resistor, with particular interest in electrical resistance as a function of Temperature Coefficient of Resistance, (TCR), length, varying composition and firing temperature. The electrical properties measured showed that the electrical resistance varied with iron content and also increased non - linearly with the length of the resistors. The peak firing temperature and firing time were found to have considerable effect on the resistance of the resistors. The resistance values fall with increasing firing temperature. All the resistors have negative TCRs with some of the resistors having TCR as low as $-3579.4 \pm 14.5$ ppm $/{ }^{\circ}$. These results are comparable with those of thermistors. Resistors of low resistance values were obtained and this largely depended on the composition of the materials used.
\end{abstract}

Keyword: Fabrication, Resistors, Lead oxide, TCR

\section{INTRODUCTION}

A resistor is an electronic component that limits the flow of current in a circuit, or provides a desired voltage drop. The various types of resistors commonly used are wire wound, composite and metal film resistors, either in bulk or thin film form. Efforts have been make to combine ceramics and metals to produce composite whose properties are better than those of either of the individual components.

The procedure for the fabrication of the resistors in this work involves compacting a mixture of $\mathrm{PbO}$ and $\mathrm{Fe}$, under suitable pressure, followed by sintering. The material obtained this way is referred to as a cermet.

In certain cermets such as $\mathrm{Cr} / \mathrm{SiO}$, composite resistors chemical reactions between the components have been reported (Cattneo et al, 1997). These cermets films like any other thin film resistors (TFRs) are not homogeneous but consist of small particles of Cromium in the matrix of $\mathrm{SiO}_{2}$ ( Forlani and Prudenziati, 1976). Cermets structured resistors, like TFRs based on $\mathrm{Bi}_{2} \mathrm{Ru}_{2} \mathrm{O}_{7}$, exhibit a high stability and very low Temperature Coefficient of Resistance (TCR) (Avadhanu and Kshirsagar, 2007, Forlani and Prudenziati, 1998). Screen printing and firing onto a substrate is a method used for producing (TFRS). The fabrication of thick film resistors involves having a paste which has three components; namely: a conductive powder, a semi conductive or insulative powder and a binder.

To select and use materials for electrical and electronic applications, we must understand how properties such as electrical conductivity and dielectrical behaviours are produced and controlled. We must also realise that electrical behaviour is influenced by the structure of the materials, the processing of the materials, and the environment to which the materials is exposed.

A composite resistor consists of a thorough mixture of an insulative or semi conductive phase, a conductive phase and a suitable binder is normally moulded into a cylindrical form. The increase in the ratio between the two materials determines the resistance of the resistors. Increase in the metallic content decreases the resistivity and vice-versa. After loading the cermets into the moulder, copper wire leads are attached to each end of the resistor. Metal migration from termination, e.g. Ag at times, does influence the resistivity of the resistor near the contacts. This gives rise to size effects noticed as dependence of the sheet resistance on the resistor length (Catteneo et al, 1980).

In the case of metal film resistors, a number of structural defects such as impurity atoms, vacancies, and interstitials, dislocations and grain boundaries are produced. The aggregate effect of these imperfections makes the resistivity of the resistors higher than their bulk counterpart. A reduction in film thickness can also lead to an increase in resistivity of a metallic film. The phenomenon of electronic conduction in material is influenced by the electronic and magnetic fields and temperature coefficients of resistance. The initial sizes of conductive and semi conducting particles affect the current noise in $\mathrm{RuO}_{2}$ thick film resistors. However, excessive light noise figures for certain $\mathrm{Pd} / \mathrm{Ag}$ conductors have been linked with interface problems in the resistor (Catteneo et al, 1980, Prudenziati et al, 1999). 
The $\mathrm{PbO} /$ Iron composite resistors, as fabricated in this work, is a mixture containing Fe grains separated by the $\mathrm{PbO}$ semi conducting medium. The mixture was subjected to a fixed $\left(1.5 \times 10^{6} \mathrm{Nm}^{-2}\right)$ pressure for complete compaction of the interatomic bonds. This pressure was applied to obtain a very hard, stable, and reliable structure. The metallic grains acts as a multivalue resistor network, through which the charge carriers move by quantum tunneling.

\section{MATERIALS AND METHODS}

An already constructed manual moulding machine was used for the production of the resistors. The lead oxide $(\mathrm{PbO})$ and iron $(\mathrm{Fe})$ were all obtained in their powdered form. These materials were of $97 \%$ purity. A GX/GF electronic balance was used to weigh each of the component materials for the cermet mixture production. The materials were then mixed to homogeneity. Small quantities of sodium metasilicate binder were added to produce a complete wetting of the mixture for enhanced compaction. A few drops of the binder was added to the cermets materials and then loaded completely into the moulder. Small metal caps of copper were attached to the ends of each resistor during moulding on which copper leads were later soldered to. The loaded cermets were all compacted under a constant pressure of $1.5 \times$ $10^{6} \mathrm{Nm}^{-2}$ for a time ranging from 2 to 3 minutes.

The applied pressure was to produce resistors of varied Iron content ranging from 90 to $97.5 \mathrm{wt} \% \mathrm{Fe}$ and that of $\mathrm{PbO}$ from 2.0 to $0.5 \mathrm{wt} \%$. All the fabricated resistors are dried within the laboratory environment for about $48 \mathrm{hrs}$ and then fired (annealed) at various firing temperatures ranging from $50^{\circ} \mathrm{C}$ to $500^{\circ} \mathrm{C}$ and time ranging from 20 to 100 minutes. Not all the resistors were considered for the research purpose after fabrication. Those with deformities ranging from displaced metal caps, cracked surface and those with unstable resistance were all discarded.

All electrical measurements were taken using digital type multimeter and were annealed at different temperatures using a muffle furnace M104. The furnace is able to maintain any pre-set temperature to within $\pm 2^{\circ} \mathrm{C}$. Each of the measurement was taken separately and the data obtained were used to plot the appropriate graphs. The variations of resistance with the following properties of the resistors were studied: length, firing temperature, firing time, composition and temperature for TCR calculation.

\section{RESULTS AND DISCUSSION}

The finished resistors are samples prepared with a constant pressure of $1.5 \times 10^{6} \mathrm{Nm}^{-2}$. The variation of resistance with length for resistors (Fig.1) showed the variation of resistance with length for resistors with $18.0 \mathrm{wt} \%$ immediately after fabrication and $18.0 \mathrm{wt} \% \mathrm{Fe}$ at $100^{\circ} \mathrm{C}$ for $30 \mathrm{mins}$. Also shown in fig.1, is the plot for 19.0 wt \% Fe immediately and 72 hrs after fabrication. A slight change of $0.05 \Omega$ in the resistance value for resistor length $1.17 \mathrm{~cm}$, immediately after fabrication and $72 \mathrm{hrs}$ after fabrication is noticed.

The variation of resistance with length for all the resistors showed a nonlinear behaviour. This is due to the mode of the distribution of impurities and defect still present in the resistors after the firing. The impurities and imperfections increased with increase in resistor length in a nonlinear fashion and this leads to a sharp increase in resistance as the resistor length is increased.
Ageing also affect the resistance of a resistor. Fig. 2 shows the variation of resistance with firing time for resistors with $18.0 \mathrm{wt} \%$ Fe fired at $300^{\circ} \mathrm{C}$ and $19.0 \mathrm{wt}$ $\%$ Fe fired both at $200^{\circ} \mathrm{C}$ and $300^{\circ} \mathrm{C}$. The relationship between resistance and firing time is a nonlinear one. The fall in the resistance value as the time is increased is due to the burning off of the organic vehicle (the binder), initiation of sintering and annihilation of defects such as vacancies (Mortem et al, 1988). As can be seen from the plots, the fall in resistance is steep in the early stage between 20 to $60 \mathrm{mins}$ after which the fall becomes gradual between 60 to 100 mins. This may have occurred because the compaction of the molecules and atoms of the resistors became complete towards the end of firing.

The leveling-off of the graph can be attributed to the completion process of attaining a value of resistance and also of the chemical reactions which might have taken place in the materials as a result of the heating - off of the chemical materials used in the cermet formation. The rate of fall depends on the peak firing temperature. The lower the value of $T_{F}$, the longer it takes for the resistor to attain fairly constant value because the processes which affect resistance changes proceed at different rates, being faster at higher $\mathrm{T}_{F}$

The variation in the ratio between the conductive phase and the resistive phase within small ranges brings about significant changes in the resistance values. It is seen that the electrical resistance has a minimum between 19.0 and $19.5 \mathrm{wt} \%$ Fe with all resistors having a constant length of $1.00 \mathrm{~cm}$ and fired at a temperature of $200^{\circ} \mathrm{C}$. The same can be seen in the same figure (fig 3) with resistors having a constant length of $0.56 \mathrm{~cm}$ and fired at the same temperature of $200^{\circ} \mathrm{C}$ for $1.5 \mathrm{hrs}$. The resistance is also minimum in this case between 19.0 and $19.5 \mathrm{wt} \% \mathrm{Fe}$.

The minimum values of resistance obtained may be due to the fact that if the ratio of the conductive phase to resistive phase attains a critical value a phase transition takes place in the materials. The minimum in the value of the resistance depends on the resistor length, being higher for resistors with longer length. The effect of size and the shape used is minimum because the size and shape used is kept constant throughout the experiment. Efforts are still going on by other researchers to find out whether the attached copper metal caps have any effect on the resistance of the shorter resistors. It is interesting to note that the result of the work carried out by Prudenziati et al on the size effects in Ru-based TFRs used resistors with different conductive termination (Pt/Au) and Ag-based composition with $\mathrm{Bi}$ added as flux in some of the conductive layers. The results obtained indicated that size effect was exhibited by resistors terminated with $\mathrm{Ag}$-based conductive terminations that have $\mathrm{Bi}$ as flux. The mechanism of conduction in these materials is due to electron tunneling by percolation (Motem et al, 1988).

Another most important parameter that greatly affected the resistance of a resistor is the firing temperature. This is because firing temperature helps in healing some of the crystal defects formed during the high pressure pressing process in the moulder and also firing the resistor helps in burning -out any resin type materials left in the resistor itself (Forlani and Prudenziati, 1998). Fig. 4 shows the variation of resistance with peak firing temperature, $\mathrm{T}_{f}$ for resistors with two different compositions. 
Bajopas Volume 2 Number 2 December, 2009

As expected, resistance variation with temperature is a nonlinear one, with resistance dropping steeply at the early stage of firing (i.e. at $T_{f}<400^{\circ} \mathrm{C}$ ). The reason for this behaviour could be attributed to the sintering of the individual particles to form continuous metal conduction paths and may also be said to have occured due to burning- off of the chemical present in the resistor. But as the temperature is increased the rate of fall slows down. This is as a result of densification that might have started initially and virtually completed at about $400^{\circ} \mathrm{C}$.

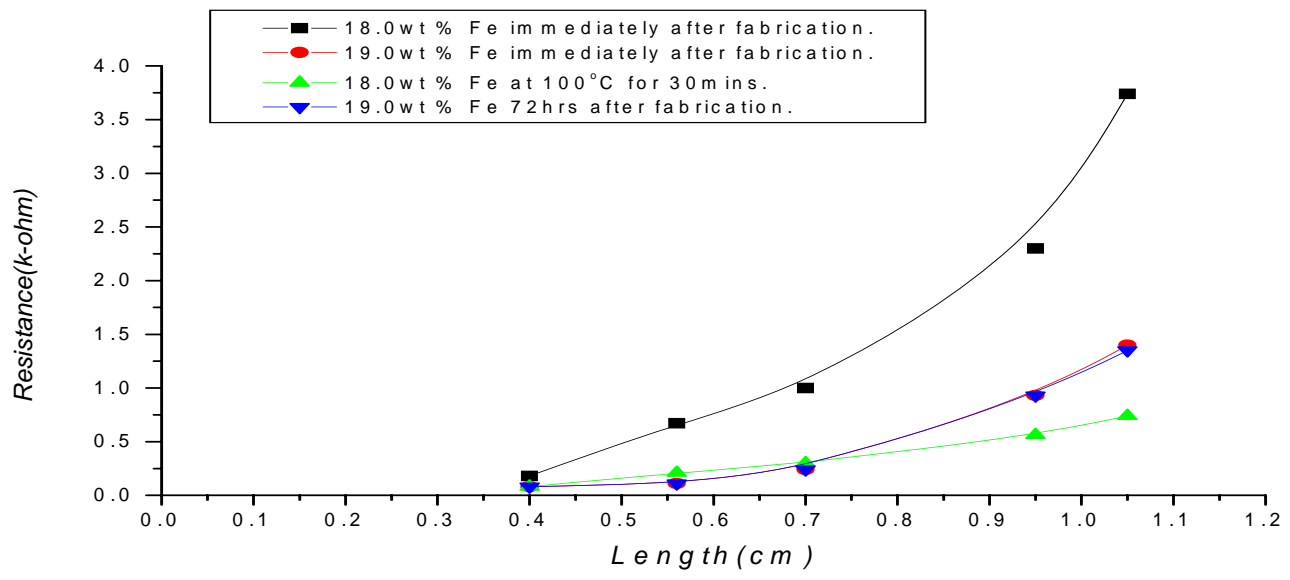

Figure.1: Variation of resistance with le $n g$ th.

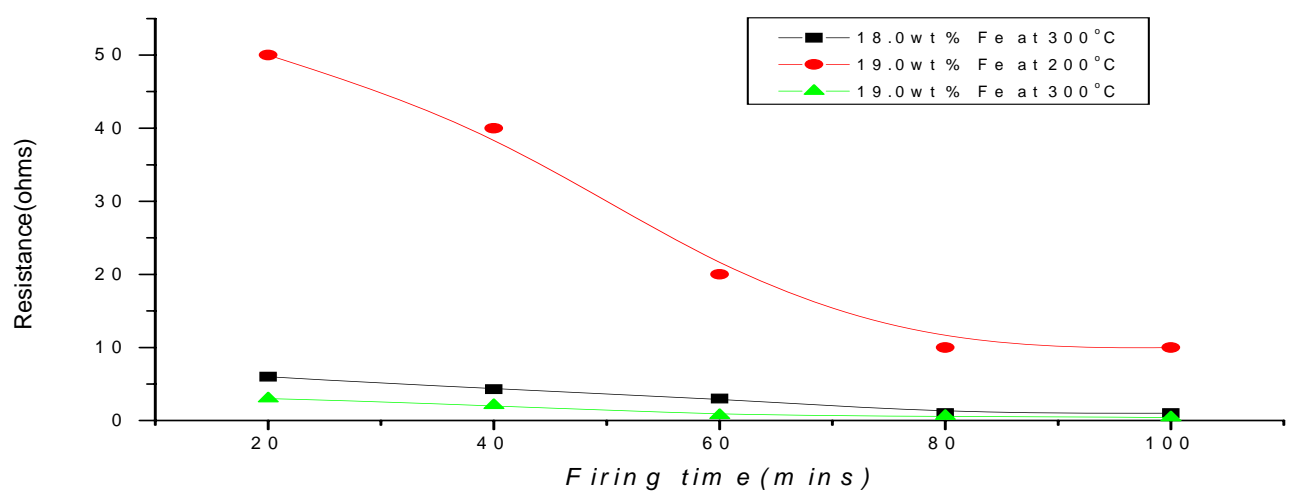

Figure.2: Variation of resistance $w$ ith firing tim e.

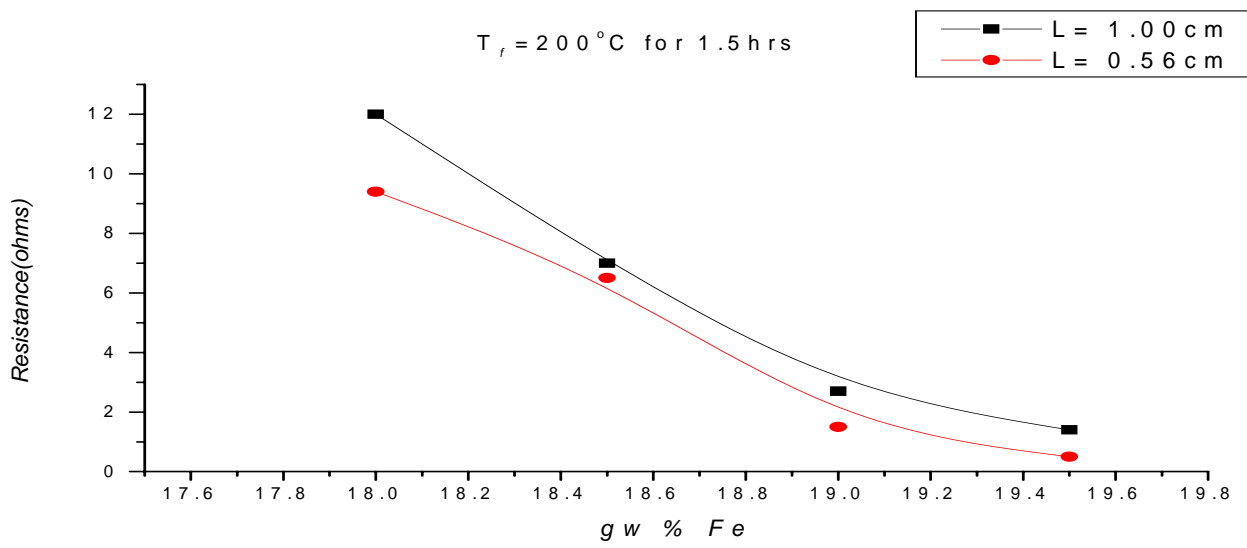

Fig.3: Variation of resistance with iron content 
Bajopas Volume 2 Number 2 December, 2009

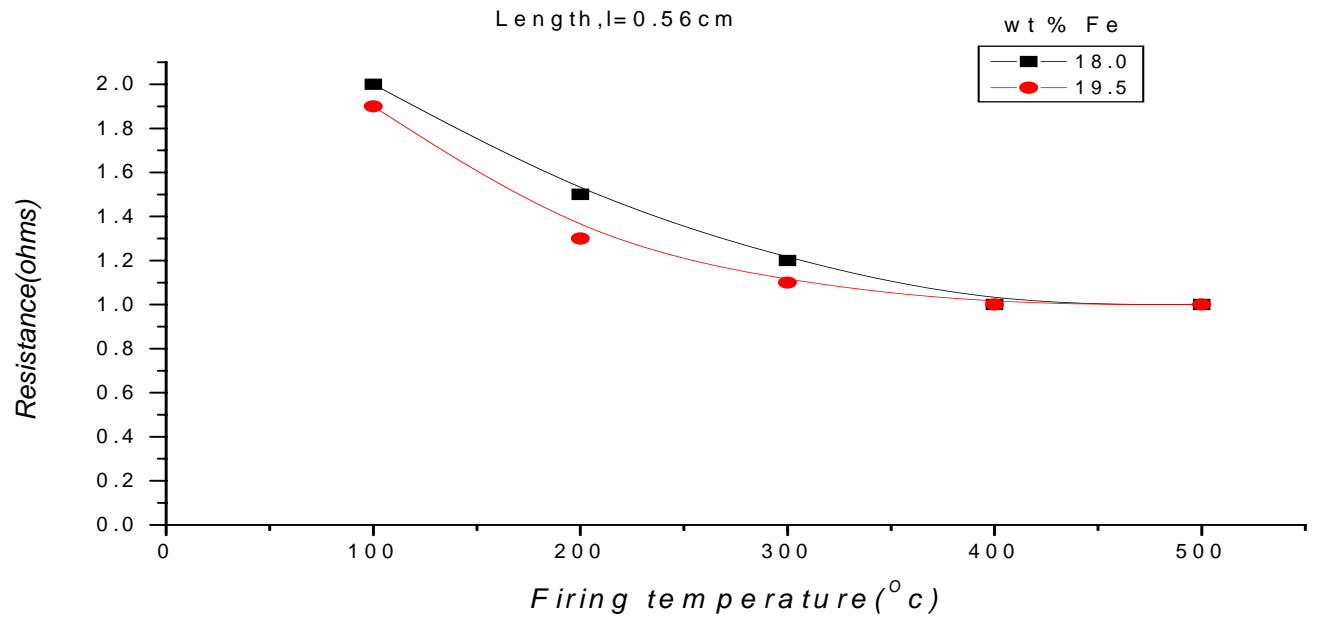

Figure.4: Variation of resistance with firing te m perature

Two different compositions of 18.0 and $19.5 \mathrm{wt} \%$ Fe both have a constant length of $0.56 \mathrm{~cm}$. The minimum resistance value started at a temperature of $300^{\circ} \mathrm{C}$ and levels-off at $500^{\circ} \mathrm{C}$. This could be due to the ratio of the conductive to the resistive components; here the resistive component is smaller than the conductive composition thereby reducing the resistance of the resistor network. Fig. 5 with 18.0 and $18.5 \mathrm{wt} \%$ Fe are for resistors having a constant length of $0.4 \mathrm{~cm}$ and show a drastic fall in the resistance of the resistor but later level off from a temperature of $300^{\circ} \mathrm{C}$ to $400^{\circ} \mathrm{C}$.

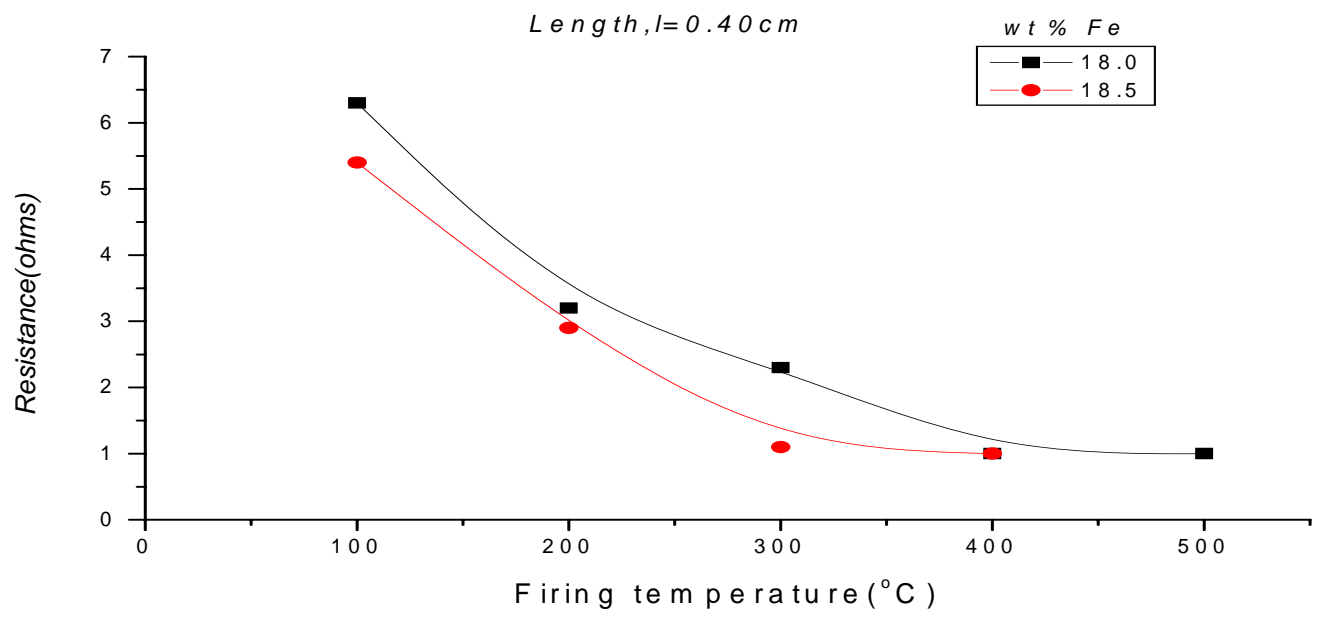

Figure.5: Variation of resistance with firing te $m$ perature.

The effect of temperature on the resistance can be explained by measuring the temperature coefficient of resistance (TCR) of the material. This is the amount of change to the resistance in relation to temperature difference expressed in pasts per million per degree
Celsius or per degree Kelvin. In this research TCR values of the fabricated resistors were obtained for content between 18.0 to $19.5 \mathrm{wt} \%$ of Fe and lead oxide between 2.0 to $0.5 w t \%$ using the equation

$T C R=\frac{R\left(T_{2}\right)-R\left(T_{1}\right)}{R_{0}\left(T_{2}-T_{1}\right)}$, where $R\left(T_{2}\right)=$ Final resistance at temperature $T_{2}$,

$R\left(T_{1}\right)=$ Initial resistance at temperature $\mathrm{T}_{1}$, and $R_{0}=$ Resistance at $0^{\circ} \mathrm{C}$, which was obtained by extrapolation at $\mathrm{T}=0^{\circ} \mathrm{C}$. 
Bajopas Volume 2 Number 2 December, 2009

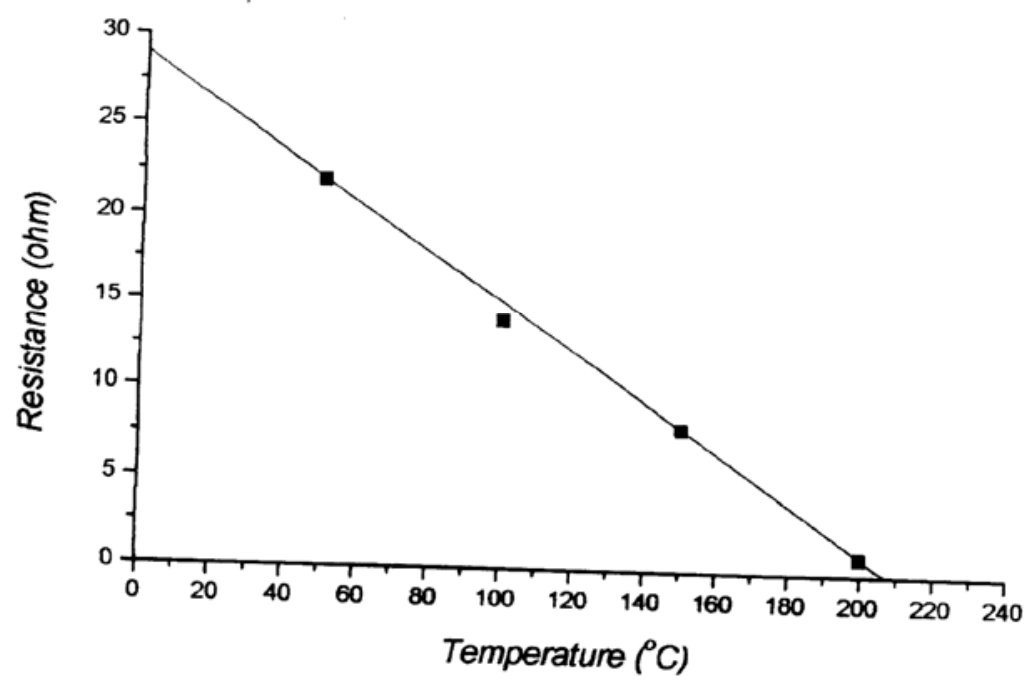

Fig.6.Variation of resistance with temperature for $18.5 \mathrm{wt} \%$ Fe (for TCR

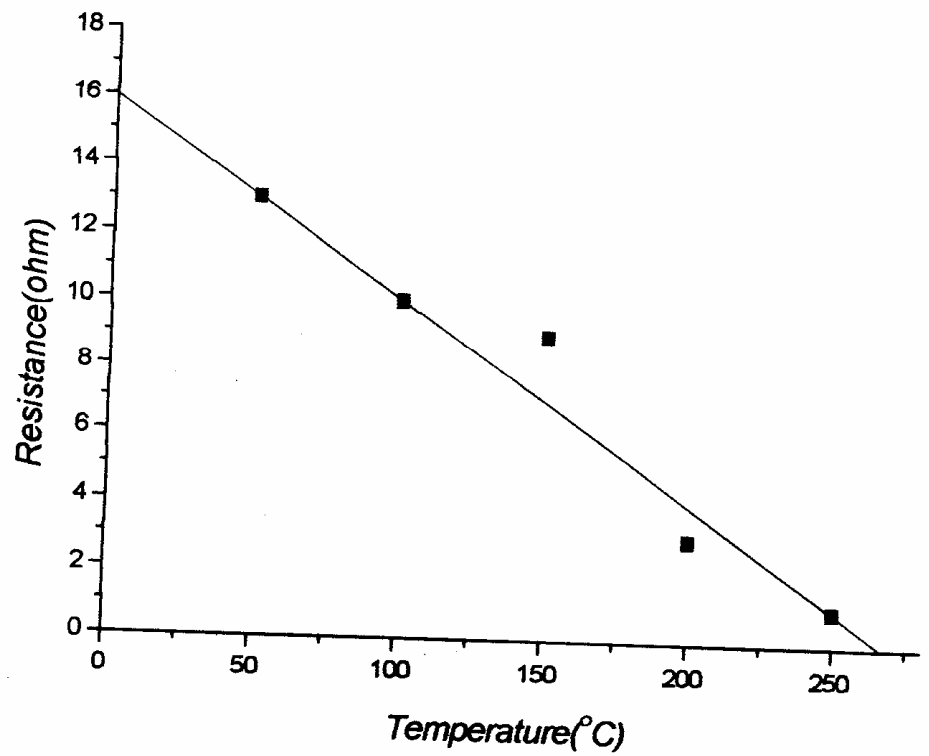

Fig.7.Vaiation of resistance with temperature for $19.0 \mathrm{wt} \%$ ( for TCR calculation)

It is observed from figures 6 and 7 that all the resistors fabricated have negative values of TCR, varying from $3579.4 \pm 14.5 \mathrm{ppm} /{ }^{\circ} \mathrm{C}$ for resistors with $19.0 \mathrm{wt} \% \mathrm{Fe}$ to $-4784.7 \pm 14.5 \mathrm{ppm} /{ }^{\circ} \mathrm{C}$ for resistors with $19.0 \mathrm{wt} \% \mathrm{Fe}$. The negative values of TCR obtained for the resistors are as a result of the mode of the electron conduction in the materials or as a result of the thermal motion of the metallic particles especially the Iron chain. This means that the gap is made smaller by pressing the cermet well which will lower the electrical resistance of the resistor. And lastly, metallic grains from the Fe-particles may have diffused into the resistive phase and give it a metallic property of being a good conductor. There could also be other material like $\mathrm{FeO}$, from the oxidation of Fe during the annealing process that may be present in the resistor that could form a conducting path in the resistive cermet. If such effect occurs at the interphase between the particles then the TCR at these region may resemble that of a heavily doped silicon $(\mathrm{Si})$ and the behavior of the resistors will find wide application in temperature sensing operation and could be useful in general purpose work where very high precision is not required. Cermet materials, like the one obtained in this work, with high and negative values of TCR have properties which are comparable to those of themistors (Rao et al,2005, Jagtap et a, 2009). 


\section{CONCLUSION}

Lead Oxide - Iron ( $\mathrm{PbO} / \mathrm{Fe}$ ) composite resistors were fabricated with the aid of a moulder and its accessories. $\mathrm{PbO} / \mathrm{Fe}$ resistive mixtures are found to be standard in thick film technology for achieving resistivity values of a few tens to a few thousands of Ohms. A constant thickness of $0.60 \mathrm{~cm}$ with varying length ranging from 0.37 to $1.17 \mathrm{~cm}$ were obtained and can meet the modern requirement for size miniaturization in circuit components. The resistors were then investigated for the influence of composition, effects of length; firing temperature and firing time on their final electrical resistance.

A minimum resistance value of $0.40 \Omega$ at $T_{f}$ of $300^{\circ} \mathrm{C}$ for $80 \mathrm{mins}$ for a resistor length of $0.37 \mathrm{~cm}$, containing 19.0wt \% Fe was observed.

The negative TCR values obtained in the work is believed to be due to the role played by the motion of $\mathrm{Fe}$ -

\section{REFERENCES}

Avadhanu, M.N; and Kshirsagar, P.G (2007): Engineering physics, Publish by $\mathrm{S}$. chand and company Itd. pp 469-510.

Catteneo, A; Cocito, M; Forlani, F; and Prudenziati, M., (1977): Electriocomponents sci. tech. Vol.4. pp205-211.

Catteneo, A; Mortem, B.; Pirozzi, L., F; and Prudenziati, M., (1980): Electriocomponents sci. tech. Vol.6. pp247-251.

Forlani, F; and Prudenziati, M., (1976). Electrocomponent science and tech. Vol. 3. pp. 77-83.

Forlani, F; and Prudenziati, M., (1998). Electrical conduction by percolation in Thick Film Resistors, Electrocomponents: Science and technology. Vol. 4.pp 509-521. grains in reducing the inter metallic gap as the temperature is increased and the role played by Iron oxide that might have been formed during the processing.

The result of this work has shown some evidence of ways in which resistors can be obtained from Iron/PbO mixture. It is also evident that cheap materials such as Iron and $\mathrm{PbO}$ can be used to produce resistors of moderate length by applying moderate firing temperatures and obtaining wide range of resistance values and negative TCR values when the iron (conductive phase) content is low.

The negative TCR values obtained for the fabricated resistors in this work are comparable to those of thermistors and imply that these resistors can be adapted for use as thermistors, if appropriate manufacturing processes are adopted.

http://www.ece.Msstate.edu/ Winton/class/ece/ece4243 /supplement chapter7. PDF. Retrieved on 28 September, 2008.

Mortem, M., Prudenziati, M., Sacchi, M., and Sirotti, J. (1988) j. Appl. Phy. 63, pp2265.

Prudenziati, M., Sirroti, F., Sacci, M., and Akomolafe, T., (1999) Active passive Electrocomponents Vol.14. pp251-269.

Rao, M. V. H., Giramkar, V. D., Phatak/ G. T., Amalner, D. P., Saski, K. S., and Shanamurthy, Y. N., (2005). Interational Jounal of Electronics, Vol. 92, No 8, pp451-466.

Jagtap, S., Rane, S., and Amalnerkar, D., (2009) Journal of Microelectronic Engineering, Vol. 86, Issue 10, pp2026-2029. 